\title{
DECADAL CLIMATE PREDICTION: OPPORTUNITIES AND CHALLENGES
}

\author{
J.W. Hurrell ${ }^{(1)}$, T. L. Delworth ${ }^{(2)}$, G. Danabasoglu ${ }^{(1)}$, H. Drange ${ }^{(3)}$, K. Drinkwater ${ }^{(4)}$, S. Griffies $^{(2)}$, \\ N. J. Holbrook ${ }^{(5)}$, B. Kirtman ${ }^{(6)}$, N. Keenlyside ${ }^{(7)}$, M. Latif ${ }^{(7)}$, J. Marotzke ${ }^{(8)}$, J. Murphy ${ }^{(9)}$, \\ G. A. Meehl ${ }^{(1)}$, T. Palmer ${ }^{(10)}$, H. Pohlmann ${ }^{(9)}$, T. Rosati $^{(2)}$, R. Seager ${ }^{(1)}$, D. Smith ${ }^{(9)}$, R. Sutton ${ }^{(12)}$, A. Timmermann ${ }^{(13)}$, \\ K. E. Trenberth ${ }^{(1)}$, J. Tribbia ${ }^{(1)}$, M. Visbeck ${ }^{(7)}$ \\ ${ }^{(1)}$ National Center for Atmospheric Research, P. O. Box, 3000, Boulder, CO 80307, USA, Email: jhurrell@ucar.edu; \\ gokhan@ucar.edu; meehl@ucar.edu; trenbert@ucar.edu; tribbia@ucar.edu \\ ${ }^{(2)}$ GFDL/NOAA (Geophysical Fluid Dynamics Laboratory/National Oceanic and Atmospheric Administration), Princeton \\ University, 201 Forrestal Road, Princeton, NJ 08542, USA, Email: tom.delworth@noaa.gov; Stephen.Griffies@noaa.gov; \\ Tony.Rosati@noaa.gov \\ ${ }^{(3)}$ University of Bergen, Allegaten 70, 5007 Bergen, Norway, Email: helge.drange@gfi.uib.no \\ ${ }^{(4)}$ Institute of Marine Research, P.O. Box 1870 Nordnes, N-5817 Bergen, Norway, Email: ken.drinkwater@imr.no \\ ${ }^{(5)}$ University of Tasmania, Private Bag 76, Hobart TAS, 7001, Australia, Email: Neil.Holbrook@utas.edu.au \\ ${ }^{(6)}$ University of Miami and Center for Ocean-Land-Atmosphere Studies, 4600 Rickenbacker Causeway, Miami, \\ FL33149 USA, Email: bkirtman@rsmas.miami.edu \\ ${ }^{(7)}$ Leibniz Institute of Marine Sciences/Research Center for Marine Geosciences (IFM-GEOMAR), Duesternbrooker Weg 20, \\ D-24105 Kiel, Germany,Email: nkeenlyside@ifm-geomar.de; mlatif@ifm-geomar.de; mvisbeck@ifm-geomar.de \\ ${ }^{(8)}$ Max Planck Institute for Meteorology, Bundesstrasse 53, D-20146 Hamburg, Germany, \\ Email: jochem.marotzke@zmaw.de \\ ${ }^{(9)}$ Met Office Hadley Centre, FitzRoy Road, Exeter, EX1 3PB, UK, Email: james.murphy@metoffice.com; \\ holger.pohlmann@metoffice.gov.uk; doug.smith@metoffice.gov.uk \\ ${ }^{(10)}$ European Centre for Medium-Range Weather Forecasts, Shinfield Park, Reading, RG2 9AX UK, \\ Email: Tim.Palmer@ecmwf.int \\ ${ }^{(11)}$ Lamont Doherty Earth Observatory of Columbia University, Rt. 9 W, Palisades, NY 10964, USA, \\ Email: seager@ldeo.columbia.edu \\ ${ }^{(12)}$ University of Reading, Harry Pitt Bld, 3 Earley Gate, Reading, RG6 6AL UK, Email: r.sutton@ reading.ac.uk \\ ${ }^{(13)}$ University of Hawaii, 2525 Correa Road, Honolulu, HI 96822, USA, Email: axel@ hawaii.edu
}

\section{INTRODUCTION}

The scientific understanding of Earth's climate system is now sufficiently developed to show that climate change from anthropogenic greenhouse gas forcing is already upon us, and the rate of change as projected exceeds anything seen in nature in the past 10,000 years. The indisputable evidence of global warming and the knowledge that surface temperatures will continue to rise over the next several decades under any plausible emission scenario is now a factor in the planning of many governments, businesses, and socio-economic sectors for which climate sensitivity and vulnerability is high. It does not imply, however, that future changes will be uniform around the globe. On the time scale of a few years to a few decades ahead, regional and seasonal variations in weather patterns and climate, and their corresponding impacts, will be strongly influenced by natural, internal variability. Decision makers in diverse arenas thus need to know the extent to which the climate events they are seeing are the product of this natural variability, and hence can be expected to reverse at some point, or are the result of potentially irreversible, forced anthropogenic climate change.

Efforts to predict the evolution of climate over the next several decades that take into account both forced climate change and natural decadal-scale climate variability are in their infancy. Many formidable challenges exist. For example, climate system predictions on the decadal time scale will require initialization of coupled general circulation models with the best estimates of the current observed state of the atmosphere, oceans, cryosphere, and land surface - a state influenced both by the current phases of modes of natural variability and by the accumulated impacts to date of anthropogenic radiative forcing. However, given imperfect observations and systematic errors in models, the best method of initialization has not yet been established, and it is not known what effect initialization has on climate predictions. It is also not clear what predictions should be attempted or how will they be verified. The brevity of most instrumental records furthermore means that even the basic characteristics and mechanisms of decadal variations in climate are relatively poorly documented 
and understood. As a consequence, the representation of natural variability arising from the slowly-varying components of the climate system differs considerably among models, so the inherent predictability of the climate system on the decadal time scale is also not well established. Demands will therefore be made on observations, particularly ocean observations, not only to describe the state of the climate system and improve knowledge of the mechanisms that give rise to decadal fluctuations in climate, but also to provide the optimal observations for decadal climate predictions and their verification.

The purpose of this paper is to outline the most significant issues and the challenges of producing skillful predictions of the evolution of the climate system on the time scale of years to decades ahead. A very brief overview of observed decadal variability and its associated impacts is presented in the following section, while a much more detailed description of the processes that give rise to such variability is presented in a companion white paper (Latif et al. 2010). Different sources of predictability on decadal time scales are described in Sect. 3, while Sect. 4 describes issues associated with initializing coupled climate models (see also the white paper by Balmaseda et al. 2010). First attempts at initialized, decadal predictions and the challenge of verifying such predictions are summarized in the following two sections, while the paper concludes with some brief comments on the particular importance of ocean observations for emerging decadal prediction systems.

\section{OBSERVED DECADAL VARIABILITY AND IMPACTS}

Global warming will continue over the next several decades under any plausible emission scenario but will inevitably be accompanied by regional scale variability and change, which can have profoundly important impacts. Examples include the Dust Bowl drought of the 1930s, the Sahelian drought of the 1970s and 1980s, the ongoing drought in the southwestern US, and decadal scale changes in Atlantic hurricane activity. They are associated with differences in land and ocean temperatures, as well as differences among the oceans. It is a central challenge of climate science to attempt to predict such regional scale climate variability and change over time scales of decades.

The most prominent example of a natural, coupled ocean-atmosphere phenomenon is the El Niño-Southern Oscillation (ENSO). El Niño events are typified by very strong warming of the central and eastern tropical Pacific Ocean with cooling over portions of the subtropics and the tropical western Pacific. These differences in regional sea surface temperature (SST) perturb the global atmospheric circulation so that some regions become warmer and wetter, while other regions cool and dry out. Historically, El Niño events occur about every 3 to 7 years and alternate with the opposite phase of belowaverage temperatures in the eastern tropical Pacific ( $\mathrm{La}$ Niña).

The nature of ENSO has varied considerably over time, however, and in recent years many studies have documented decadal and longer-term variability of ENSO and Pacific climate in general (e.g., as reviewed by Trenberth et al. 2007). Decadal to inter-decadal variability in the atmospheric circulation is especially prominent in the North Pacific (e.g., Trenberth and Hurrell 1994) where fluctuations in the strength of the wintertime Aleutian Low pressure system co-vary with North Pacific SST (Fig. 1, top) in what has been termed the "Pacific Decadal Oscillation" or PDO (e.g., Mantua et. al. 1997). Very similar time scale fluctuations in SST and atmospheric and ocean circulation are present across the whole Pacific Basin, and these variations are known as the Inter-decadal Pacific Oscillation (IPO; Power et al. 1999a; Folland et al. 2002). Phase changes of the $\mathrm{PDO} / \mathrm{IPO}$ are associated with pronounced changes in temperature and rainfall patterns across North and South America, Asia and Australia (e.g., Power et al. 1999b; Deser et al. 2004; Micevski et al. 2006), as well as important ecological consequences, including major shifts in distribution and abundance of zooplankton and important commercial species of fish (Hare and Mantua 2000). Furthermore, ENSO teleconnections on interannual time scales around the Pacific basin are significantly modified by the PDO/IPO.

The inter-decadal time scale of tropical Indo-Pacific SST variability is likely due to oceanic processes. In another OceanObs'09 white paper, Latif et al. (2010) describe the mechanisms likely responsible for observed decadal variations in climate, not only over the Pacific but also over the Atlantic sector. There, in contrast to the tropical Pacific, decadal variability has large amplitude relative to interannual variability, especially over the North Atlantic (e.g., Schlesinger and Ramankutty 1994; Enfield et al. 2001; Knight et al. 2005). Multi-decadal variability in the SSTs in the Atlantic has been termed the "Atlantic Multidecadal Oscillation", or AMO (Fig. 1, bottom). Instrumental records are not long enough to determine whether this variability has a well-defined period rather than a simpler character, such as "red noise". The robustness of the signal has therefore been addressed using paleoclimate records, and similar fluctuations have been documented through the last four centuries (e.g., Delworth and Mann 2000). Numerous modelling studies 
have examined potential links between the AMO and the Atlantic Meridional Overturning Circulation (MOC), but the nature of the observed relationship is unclear owing to a lack of long-term, continuous, records of the MOC. There is clear evidence, however, of decadal variability in the heat and freshwater content of the Atlantic Ocean (e.g., Lozier et al. 2008), as well as evidence of ocean circulation changes in recent decades (e.g., Hakkinen and Rhines 2004; Curry and Mauritzen 2005) that have likely played an important role in the evolution of the Atlantic SSTs.

The slow changes in Atlantic SSTs have affected regional climate trends over parts of North America and Europe (e.g., Enfield et al. 2001; Sutton and Hodson 2005), hemispheric temperature anomalies (Zhang et al. 2007), sea ice concentration in the Greenland Sea (Venegas and Mysak 2000), Arctic Ocean conditions (Polyakov et al. 2004), hurricane activity in the tropical Atlantic and Caribbean (e.g., Webster et al. 2005; Zhang and Delworth 2006; Trenberth and Shea 2006) and fisheries production in the northern North Atlantic (Drinkwater 2006). In addition, tropical Atlantic SST anomalies have contributed to rainfall anomalies over the Caribbean and the Nordeste region of Brazil, and severe multi-year droughts over parts of Africa including the Sahel (e.g., Bader and Latif 2003, Giannini et al. 2003, $\mathrm{Lu}$ and Delworth 2005; Hoerling et al. 2006). Tropical Atlantic SST variations are also a factor in producing drought conditions over portions of North America, although tropical Pacific SST variations appear to play a more dominant role (e.g., Schubert et al. 2004; Seager et al. 2005, 2008; Seager 2007).

This brief survey of observed decadal climate variability makes it clear that, on the regional scales on which most planning decisions are made, anthropogenic climate change signals will be strongly modulated by natural climate variations, and especially those driven by the slowly varying oceans on a time scale of decades. This non-uniformity of change highlights the challenges of regional climate change that has considerable spatial structure and temporal variability. Moreover, it illustrates the need to predict not just the change in global mean temperature, but the patterns of SSTs around the globe as accurately as possible. A robust ocean observing system will be crucial to such decadal climate predictions.
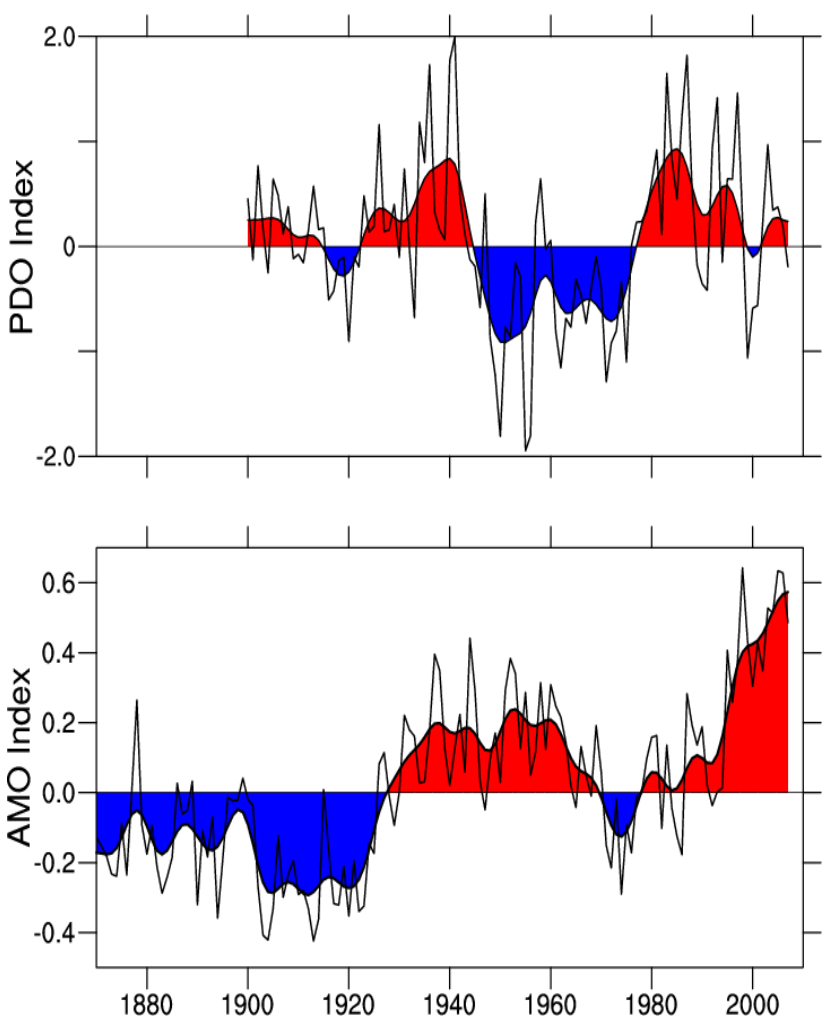

Figure 1. Top panel: Pacific Decadal Oscillation, as denoted by annual SST based on the leading EOF SST pattern for the Pacific basin north of $20^{\circ} \mathrm{N}$, updated from Mantua et al. 1997. The color fill in both the upper and lower panels is from a low-pass symmetric filter with 13 total weights and a half-power point at 16 year period, with the end points reflected. Bottom Panel: Atlantic Multi-decadal Oscillation, as denoted by the low-pass filtered time series of annual SST anomalies averaged over the North Atlantic $\left(0-60^{\circ} \mathrm{N}, 0-80^{\circ} \mathrm{W}\right)$ relative to 1901 to $1970\left({ }^{\circ} \mathrm{C}\right)$. The color fill depicts the low-pass filtered SST, and the solid lines are annual means. Updated from Trenberth and Shea (2006). 


\section{SOURCES OF PREDICTABILITY}

\subsection{External forcing}

A significant source of predictability on the decadal time scale is associated with radiative forcing changes. Past emissions of greenhouse gases have committed the climate system to future warming as the ocean comes into equilibrium with the altered radiative forcing (Hansen et al. 2005; IPCC 2007). Changes in solar irradiance and volcanic activity in the recent past also can provide some level of decadal predictability as the climate system responds to these forcing changes on decadal scales.

The best possible estimates of future radiative forcing changes are also needed for predictions. Estimates of future emissions of radiatively important pollutants are needed for making predictions, as well as modeling capabilities to accurately simulate both how these pollutants affect the global energy, carbon and sulfur cycles, and how the climate system subsequently responds to that altered forcing. In this regard, future external forcing from greenhouse gases is likely to provide significant regional decadal predictability (e.g., Lee et al. 2006), since the increase of concentrations over the next 30 years is about the same no matter what emission scenario is followed (Hibbard et al. 2007). While man-made aerosols can be washed out of the atmosphere by rain in just a few days, they tend to be concentrated near their sources such as industrial regions, and can affect climate with a very strong regional pattern. Future changes in anthropogenic aerosols, therefore, could have very significant regional climatic impacts on decadal scales. Unpredictable volcanic eruptions can be a significant "wild card" to decadal climate predictions, although techniques to handle this aspect are under consideration. Similarly, only very general features of the 11-year solar cycle can be projected, but could provide some decadal scale predictability. The influence of the stratosphere, by transmitting external forcing signals to the troposphere, might also be a significant source of predictability.

\subsection{Natural internal variability}

There have only been a handful of efforts to assess the predictability of the tropical and extratropical ocean state, especially on decadal to inter-decadal time scales. A classic measure of predictability is how rapidly two similar states diverge from each other with predictability being lost when the two states are as far apart as two randomly chosen states. Using a 40-member ensemble of Community Climate System Model (CCSM-3; W. D. Collins et al. 2006) simulations that differ only in their initial atmospheric states, for the globe as a whole the limit of predictability for annual means of average upperocean temperature is about a decade (Fig. 2). There is less predictability of the global SST field because of the stronger influence of high-frequency atmospheric variability on surface temperature. The results in Fig. 2 are model dependent and could change with better models.

\section{Global RMSD in 40-member ensemble (780 pairs)}

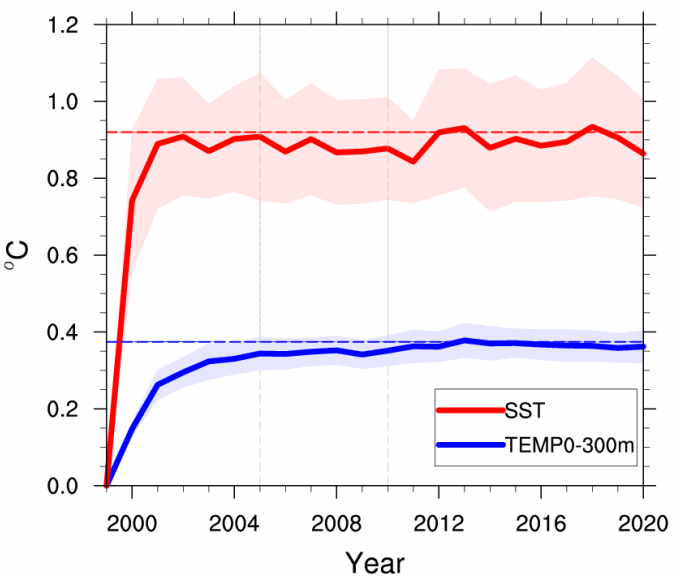

Figure 2. Global Root-Mean-Square-Difference (RMSD) in surface and upper-ocean $(0-300 \mathrm{~m})$ temperature from 780 pairs of coupled climate model simulations, derived from an ensemble of 40 simulations. Each simulation differs only in the specification of the initial atmospheric state. The RMSD from completely random states are given by the horizontal, dashed lines. Courtesy of Grant Branstator and Haiyan Teng.

Regionally, the predictability of SST can be higher than for the global field (not shown), with the highest levels on decadal time scales over the middle to high latitude ocean areas of both hemispheres, especially in regions where the surface layer makes contact with the deeper ocean beneath (Boer and Lambert 2008). A fundamental precept in predictability is the notion that long-lived variations, such as those associated with the PDO or changes in the strength of the Atlantic MOC, can be predicted for a significant fraction of their lifetimes. This is simply a reflection of the fact that the persistence of the variation implies a stable balance that permits the variation to have an extended lifetime. Thus, there is some confidence that naturally occurring climate variations with decadal time scales can, at times, be predictable given an accurate initial state. These times are likely to be when a significant amplitude variation exists. At other times, particularly the nascent phase of variation growth, the predictability of variations is likely to be quite delicate and require a very accurate depiction of the 
current state of the climate system if there is to be any hope of accurate prediction.

Studies of simulated variability help to identify signals of potential predictability. For the Atlantic MOC, Delworth et al. (1993) found damped oscillatory MOC variability with a 50-year time scale. Griffies and Bryan (1997) demonstrated decadal predictability for several ocean fields in the GFDL (Geophysical Fluid Dynamics Laboratory) model, and M. Collins et al (2006) found comparable levels of predictability in several independent climate models. Such studies, while provocative, are however limited by the fidelity of the models used and insufficient observations to fully evaluate the physical relevance of the simulations.

The Atlantic MOC index is shown from eight different coupled climate model simulations in Fig. 3. Several points are salient to the decadal prediction problem:

The amplitude and spectra (not shown) of the MOC variability span a wide range, with some models showing periods of quasi-regular multi-decadal oscillations and others showing highly-damped variations whose power is focused more on interannual time scales. Perfect model predictability experiments would likely show correspondingly distinct behaviors.

The GFDL simulations CM2.1, CM2M, and CM2G use identical atmosphere, sea ice, and land models. Only the ocean model configurations differ; yet, the simulated Atlantic MOC variations exhibit considerable differences, with $\mathrm{CM} 2 \mathrm{G}$ illustrating very little power at the decadal time scale. Such results illustrate the potential sensitivity of simulated variability to details of the ocean configuration and the corresponding representation of ocean processes.

In the CCSM-3 simulations, both the mean value of the Atlantic MOC and the amplitude of its variability have significant dependency on the atmospheric resolution (Bryan et al. 2006, Danabasoglu 2008). There is a 20year period of variability in both model configurations, in contrast to the longer-term variability evident in CCSM-4.

e paucity of observational data precludes a definitive statement as to which simulation best approximates nature. However, no model replicates time series like the observed AMO.

The above results highlight some fundamental challenges and requirements, since the feasibility of decadal predictions largely stems from the role the ocean plays in the predictability of slowly evolving modes of variability. The challenge then is to have the capability to accurately represent this low frequency climate variability within climate models, so that initializing them offers the potential to predict the internal variability of the real climate system. To improve the representation of the internal variability in models, it will be necessary to compare and contrast the physical mechanisms that give rise to the simulated variability, with the goal of establishing organizing principle(s) to rationalize the wide-ranging simulation behaviors evident in Fig. 3. Such analyses will ultimately lead to an assessment of the importance of certain physical processes for setting the simulated variability, as well as to an improved

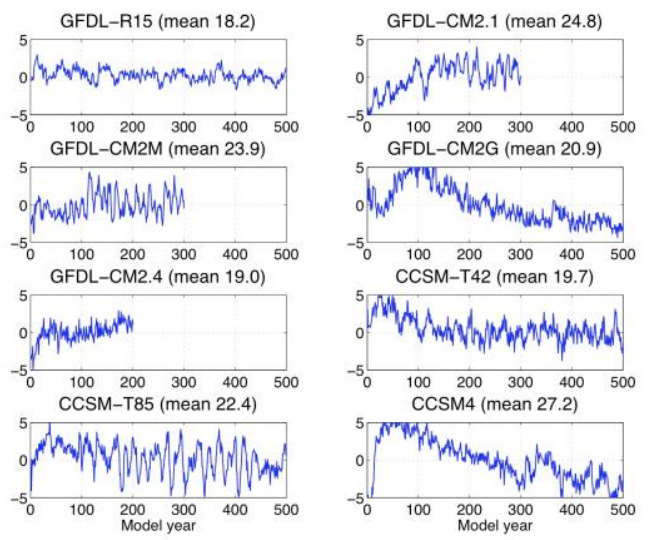

Figure 3. Atlantic MOC index from a suite of coupled climate models. Values plotted are departures from the respective long-term means (listed along top of each graph). Units are Sverdrups ( Sv; $\left.1 \mathrm{~Sv}=10^{6} \mathrm{~m}^{3} \mathrm{~s}^{-1}\right)$.

GFDL-R15 is from Delworth et al. (1993); GFDL-CM2.1 is from Delworth et al. (2006). CM2M and CM2G are prototype models developed for the AR5 IPCC simulations, with each model using the same atmosphere, sea ice, and land used in CM2.1, but with CM2M using updated ocean physics and CM2G using an isopycnal coordinate ocean. CM2.4 uses a 1/4 ${ }^{\circ}$ square grid ocean component (with roughly $12 \mathrm{~km}$ horizontal resolution in the North Atlantic) and a $1^{\circ}$ atmosphere that uses the same physics as the $2^{\circ}$ CM2.1 atmosphere. CCSM-3 T42 and T85 (W. D. Collins et al. 2006) use the same atmosphere, sea-ice, land, and ocean models, but differ in the horizontal resolution of the atmospheric model. In

both, the ocean model has a nominal $1^{\circ}$ horizontal resolution. CCSM4 represents a prototype simulation that uses newer physics in all components with a nominal $2^{\circ}$ horizontal resolution, finite-volume dynamical core atmosphere and a nominal $1^{\circ}$ ocean model.

representation of those processes in models. Paleoclimate reconstructions will also play an important role in constraining the model-simulated variability.

Finally, it should be noted that many climate and biogeochemical variables exhibit long-term persistence 
that could be exploited using statistical forecasting schemes. Physical damping of high-frequency variability increases the decadal signal to noise ratio and hence the potential predictability on decadal timescales. Simple linear multivariate decadal prediction schemes that exploit the long-term damped persistence of certain physical processes may, in fact, be quite successful (e.g., Lean and Rind 2009), but they rely heavily on long-term data sets to accurately estimate the covariance matrix. With their potential for long records, paleoclimate reconstructions may be of use in estimating such statistical relationships and developing predictive models. For example, Enfield and Cid-Serrano (2006) developed a statistical model for predicting regime shifts in the AMO; similar methodology could be applied for other climatic shifts.

\section{INITIAL CONDITIONS}

An important research question is "How accurately must the initial state be described to yield outlooks that are useful to society?" Prediction of the full-coupled climate system requires an initial state to be specified based upon observations and a data assimilation system. All sorts of atmospheric observations are routinely processed in real time for numerical weather prediction purposes, and surface fields, including fluxes potentially useful for coupling, result from these analyses. However, surface fluxes of a reanalysis atmospheric model with specified SSTs are typically biased (e.g., Trenberth et al. 2009) and can be very wrong as the ocean acts as an infinite heat and moisture source or sink.

For climate predictions, the initial state of the atmosphere is less critical, but the initial states of other climate system components are vital. For predictions of a season to a year or so, the SSTs, sea ice extent and upper ocean heat content, soil moisture, snow cover, and state of surface vegetation over land are all important. Such initial value predictions are already operational for forecasting El Niño, and extensions to the global oceans are under way. For the decadal prediction problem, increased information throughout the ocean could be essential (Smith et al. 2007; Trenberth 2008; Meehl et al. 2010; Shukla 2010).

Initialization has three main components: the observing system, the assimilation method, and the model. These three components are combined to produce initial conditions for the climate model. One needs to keep in mind that the initialization problem is different from the state estimation problem. Next, we examine each component and its relation to decadal prediction problem, focusing on the role of the ocean.

\subsection{The Observing System}

Historically the sub-surface ocean has been very sparsely observed, and some of the data appear to be significantly biased (Domingues et al. 2008), making the development and testing of ocean initialization schemes difficult. For instance, the non-stationary nature of the ocean observing system (Fig. 4), particularly due to the paucity of salinity data as well as XBT (Expendable Bathythermograph) data only going to $500 \mathrm{~m}$, can give rise to spurious decadal variability making the assessment of forecasts difficult.

Number of Temperature Observations per Month as a Function of Depth

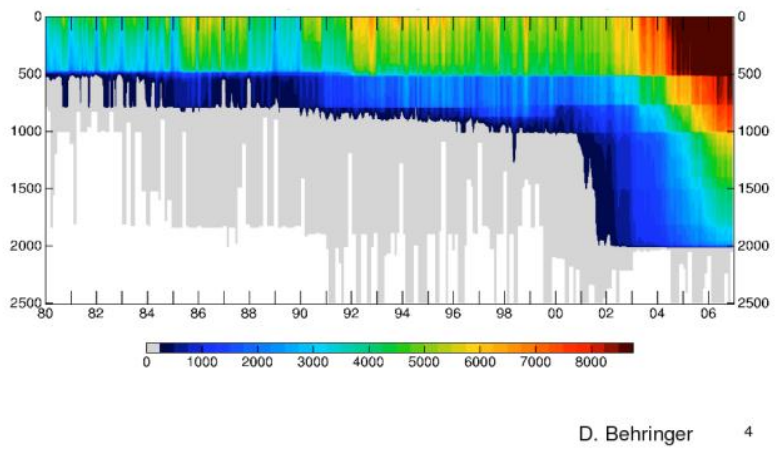

Figure 4. The global number of temperature observations per month as a function of depth. The data sources are

XBTs, fixed tropical moorings (TAO (Tropical Atmosphere Ocean) (Pacific), TRITON (Triangle TransOcean Buoy Network) (Pacific), PIRATA (Prediction and Research Moored Array) (Atlantic), and the developing

Indian Ocean array) and Argo floats. The apparent

horizontal strata reflect the successive influence of $450 \mathrm{~m}$ XBTs, 750 m XBTs, 500 m TAO-class moorings and 1000 $m$ and $2000 m$ Argo floats.

Studies of historical periods are important in order to assess the likely skill of forecasts over a range of different climate states. Recent and planned improvements to the observational network, however, offer significant potential for improvements in future forecast skill. Perhaps most important among these is the recent (2003) deployment of a global array of profiling floats by the Argo program (Freeland et al. 2010). These provide for the first time contemporaneous measurements of both temperature and salinity over the upper $2 \mathrm{~km}$ of the global ocean, potentially offering a step change in our ability to initialize ocean heat and density anomalies. These measurements, for instance, are likely critical in order to make useful predictions of the Atlantic MOC (see Fig. 5 of Balmaseda et al. 2010). Another important recent contribution is the altimetry data that, in addition 
to its own merits, holds great promise in conjunction with Argo.

\subsection{The assimilation method}

A simple approach that avoids the difficulties with historical sub-surface ocean observations is to initialize models by assimilating only SSTs (Keenlyside et al. 2008), relying on ocean transport processes in the model to initialize the sub-surface ocean indirectly. An alternative approach (being tested at NCAR (National Center for Atmospheric Research) and MPI (Max Planck Institute) is one in which sub-surface ocean temperature and salinity are diagnosed from an ocean model forced by atmospheric observations, then nudged into a coupled model to produce initial conditions for forecasts. The direct use of sub-surface ocean observations, however, would be expected to improve forecast skill.

Several reanalyses of historical ocean observations have been constructed and are being evaluated through the CLIVAR (Climate Variability and Predictability) GSOP (Global Synthesis and Observations Panel) intercomparison project. Temperature and salinity from two of these have already been used to initialize models for decadal forecasts (Smith et al. 2007, Pohlmann et al. 2009). In this way, modeling groups without data assimilation schemes can perform initialized climate predictions. Ocean data assimilation is used operationally in several prediction centers around the world to initialize seasonal forecasts with coupled models, and it is from that experience that decadal prediction efforts will build (Balmaseda et al. 2010). Ultimately, however, fullycoupled data assimilation schemes that take advantage of covariances between ocean and atmospheric variables to generate an optimal estimate of the climate system are expected to offer the greatest forecast skill. Such schemes are under development with some encouraging results (e.g., Zhang et al. 2007).

\subsection{The model}

Although idealized model experiments show considerable promise for predicting internal variability, particularly in the North Atlantic (e.g., M. Collins et al. 2006; Hurrell et al. 2009), there are technical obstacles that must be overcome if such potential predictability is to be achieved in reality. The problem of model error, as discussed in Sect. 3b, is critical for decadal prediction, since the sub-surface ocean state associated with the initial condition may be significantly different than the climate of the free running coupled model. As a consequence, at forecast initialization, the coupled model rapidly adjusts away from the observed climate estimate towards the coupled model climate that is itself a product of its own systematic errors. This is often referred to as an "initialization shock" or "coupling shock". Is simple bias correction sufficient to remove the effects of model drift, or is the non-linearity of climate such as to cause bias to destroy any useful predictability that may exist on the decadal timescale?

Another approach, known as "anomaly initialization" (Schneider et al. 1999), has therefore been tried (Smith et al. 2007, Keenlyside et al. 2008, Pohlmann et al. 2009) to avoid the systematic error. In this, models are initialized with observed anomalies added to the model climate, rather than initialized with observed values, and the model climate is removed to obtain forecast anomalies. However, the relative merits of bias correction and anomaly assimilation have yet to be quantified on decadal timescales. Nevertheless, with the current generation of ocean data assimilation systems and coupled models, it is possible to demonstrate the benefits of assimilating ocean data for the decadal forecast skill.

\section{DECADAL PREDICTIONS}

\subsection{First Attempts}

Prediction of observed decadal variations in climate is in its infancy (Murphy et al. 2009). To date there have been two sensitivity studies (Pierce et al. 2004, Troccoli and Palmer, 2007) and three extended hindcast experiments (Smith et al. 2007, Keenlyside et al. 2008, Pohlmann et al. 2009) that investigated the impact of initializing climate projections from an observed state. The sensitivity studies found little additional predictability from initialization, over that due to changes in external radiative forcing, on global (Pierce et al. 2004) and regional scales (Troccoli and Palmer 2007). However, neither study considered more than two start dates.

The extended hindcast experiments have shown enhanced skill from initialization at global scale (Smith et al. 2007) and over the North Atlantic (Keenlyside et al. 2008; Pohlmann et al. 2009). These studies took a very similar approach: initializing a global climate model using observed anomalies and running it forward ten years, while accounting for changes in external forcing (natural and anthropogenic). However, the initialization technique, data and models were different and gave rise to different results. Whereas Smith et al. (2007) demonstrated that initialization leads to better for global mean temperature over the past nearly three decades of recent warming, the results of Keenlyside et al. (2008) and Pohlmann et al. (2009) were less convincing over the longer period (Fig. 5, top). The latter two studies demonstrated enhanced skill, however, in the North Atlantic Sector (Fig. 5, bottom). Predictability of global mean temperature arose from initialization of upper 
ocean heat content (Smith et al. 2007), whereas for North Atlantic SST it was from the Atlantic MOC. Hence, it

(A) Global overage surfoce temperature

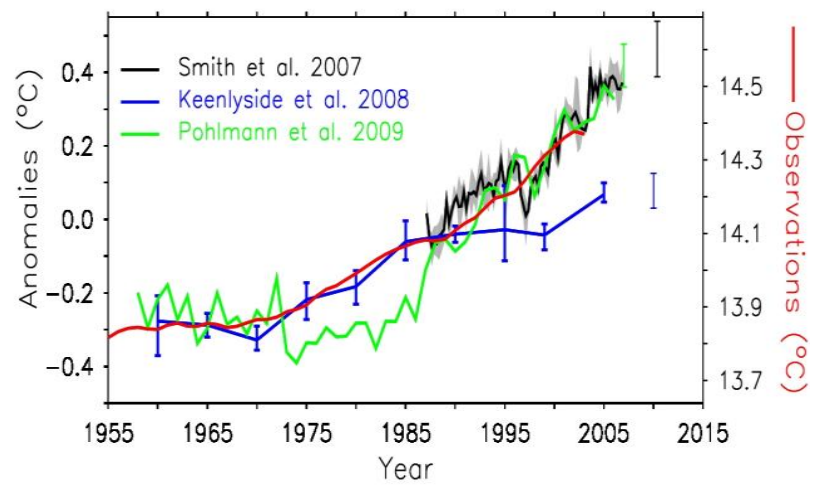

(B) Atlantic SST dipole index

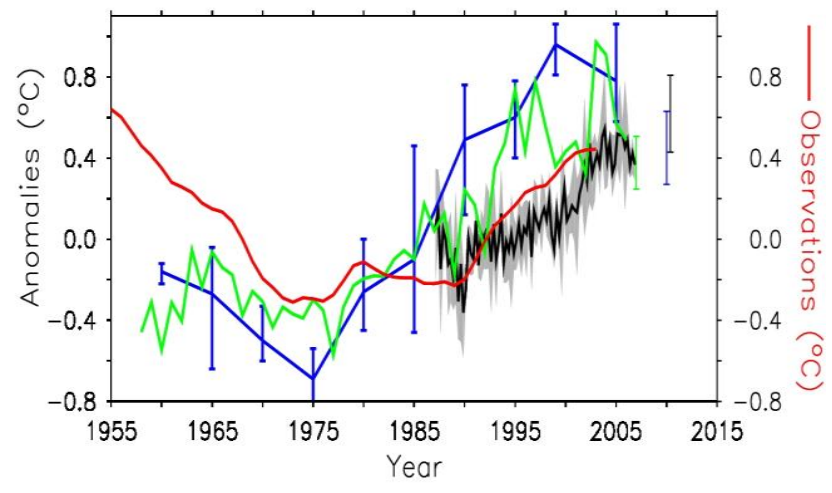

Figure 5. Observed and hindcast ten year mean (top) global surface temperature and (bottom) Atlantic SST dipole indices. The latter is sometimes used as a proxy for MOC fluctuations and is defined as the SST average difference 60-10W, 40-60N minus 30W-10E, 10-40S.

Hindcasts for Smith et al. (2007) begin in 1982, with one per season and four ensemble members (spread shaded);

Keenlyside et al. (2008) begin in 1955, with one every five years and three ensemble members (vertical bars); and Pohlmann et al. (2009) begin in 1953, with one per year. Separate vertical bars centered on the predicted period show future forecasts. The Pohlmann et al. (2009) forecast has seven ensemble members. Smith et al. (2007), Keenlyside et al. (2008), and Pohlmann et al. (2009) hindcasts have been adjusted to have the observed means over the 1979-2001, 1955-2005, and 1953-2001 periods, respectively. Observations are from HadISST

\section{1 and HadCRU3.}

may be speculated that differences among these systems comes primarily from different initialization strategies, which is partly supported by the fact that Keenlyside et al. (2007) and Pohlmann et al. (2009) used essentially the same model. Future ten-year projections from these systems also came to somewhat different outcomes (Fig. 5).

\subsection{Single versus multiple model predictions}

Differences in the results from the initial decadal prediction efforts discussed above also likely arise from model differences, highlighting the potential importance of a multi-model approach to prediction as is being investigated, for instance, in the EU-Project ENSEMBLES (Ensemble-based Predictions of Climate Changes and their Impacts) (http://www.ensembleseu.org). The need for ensemble prediction for weather is well established based on the fact that the atmosphere is chaotic and therefore sensitive to initial condition uncertainty.

There has been considerable debate in the literature regarding ensemble generation techniques. In terms of sub-seasonal to interannual time scale variability, the climate system clearly exhibits sensitive dependence on initial conditions. For example, Stan and Kirtman (2008) argue that forecast errors in some ENSO predictions are dominated by initial condition errors. On decadal to multi-decadal time scales, the sensitivity to initial conditions is not firmly established, but could very well be important, particularly when considering quantifying the climate change commitment.

Sensitivity due to uncertainty in model formulation can also have a significant impact on predictability (Palmer et al. 2005). This sensitivity is associated with the uncertainty in sub-grid scale parameterized physics and model numerics. The recognition of the importance of this sensitivity has led to a number of efforts that have demonstrated that a multi-model ensemble strategy is the best current approach for adequately resolving forecast uncertainty and the forecast probability distribution in seasonal-to-interannual predictions (Kirtman and Min, 2009; Palmer et al., 2008; Doblas-Reyes, 2005; Hagedorn et al. 2005; Palmer et al. 2004). Another recently proposed methodology is to use stochasticdynamic parameterization techniques, which perturb parameterizations in such a way as to improve on the benefits of a multi-model ensemble by using a single model (Palmer et al. 2009).

\section{VERIFICATION}

How to evaluate decadal hindcasts and predictions is a major challenge. A quick scan through the literature reveals a dizzying array of different climate metrics both interesting and important. Furthermore, the attraction to use metrics to select the "best" model for a climate application is problematic (Gleckler et al. 2008). Metrics 
differ in variable, time scale, space scale, or functional representation. The same is not true in weather prediction, where some estimates of both prediction limits and the impact of different weather prediction metrics can be determined. Moreover, the skill of daily weather forecasts can be verified many times and a quantification of model skill is relatively straightforward.

The problem is more difficult for seasonal prediction, since a large number of seasons and those forecast states must pass in order to build up forecast verification statistics. For decadal and longer time scales, the problem of quantifying prediction skill becomes even more difficult, and the metrics will likely involve how the forecasts are used in applications (Vera et al. 2009). One important issue is how to accumulate enough forecasts for quality assessments. The use of hindcasts is a typical approach (Sect. 5); however, the lack of initialization data and the non-stationary nature of observing systems, as well as the climate system itself, are difficult issues that must be addressed. For instance, forecasts benefiting from Argo data are potentially significantly more skillful than hindcasts based on very sparse historical observations (Balmaseda et al. 2010; see also Sect. 4). Extending the climate record back in time using paleoproxy data-based climate reconstructions is hence of paramount importance and should be an integral part of decadal prediction research.

In general, decadal forecasts will be probabilistic in nature. There are two key elements in determining the quality of a probability forecast: reliability and resolution (Hsu and Murphy 1986). Reliability can be described as follows: in a set of forecasts where an event is predicted with a (say) $60 \%$ probability, the forecast system is reliable if the event occurs in reality, within this set, $60 \%$ of the time. In practice, because of model bias and other generic model shortcomings, single model ensembles are not reliable in this sense. Multi-model ensembles are more reliable than single model ensembles (Palmer et al. 2004) but also cannot be said to be fully reliable (Palmer et al 2009). Empirical corrections can be made to make the ensembles more reliable, but having to apply such empirical corrections is undesirable, especially since the decadal prediction problem is a nonlinear problem and the empirical correction methods are essentially linear. Evidence is starting to emerge that stochastic parameterization provides an alternative to the multimodel technique, in which reliability is improved (Palmer et al. 2009).

The second element in determining the quality of a probability forecast is resolution. A system with "resolution" will forecast different probabilities according to whether the forecast event verifies or not.
Hence a system that always predicts the climatological probability for some binary event, irrespective of whether or not the event verifies, will be reliable but have no resolution. A key goal of decadal prediction research is to establish that decadal prediction probabilities do indeed have some resolution, arising from predictable elements of the climate system such as the Atlantic MOC.

\section{CONCLUDING REMARKS}

Ocean observations will be at the heart of decadal climate prediction systems. Major challenges will, therefore, be to continually assess whether existing and planned ocean observing systems are also well suited for initialization and verification of decadal predictions and to address any identified deficiencies.

As for seasonal-to-interannual climate predictions, most likely a range of prediction approaches will be used for the decadal time scale. Some early results indicate that the overturning circulation in the ocean can provide some level of useful predictability. Full water column observations will therefore likely be needed to properly initialize coupled system models. A tremendous advance has been the measurements of temperature and salinity over the upper $2000 \mathrm{~m}$ of the global ocean currently provided by Argo profiling floats. There exists, however, a need to assess whether observations from below 2000 $\mathrm{m}$ would be of use in decadal climate predictions by more completely characterizing deep ocean conditions. Verification of decadal predictions will also benefit from sustained moored time series observations, such as those already partially implemented by the OceanSITES (OCEAN Sustained Interdisciplinary Time series Environment observation System) group.

Instrumental errors of roving observing systems (e.g., Argo) remain a challenge, as do aliasing effects (due to mesoscale ocean eddies) from course resolution observations in time and space. It might be beneficial to sustain a dense observing system in critical regions for a decade or so in order to assess the requirements on spatial scales and depth resolution for decadal information. An excellent recent example is the RAPID/MOCHA array (a collaborative project, partnered with the UK Natural Environment Research Council RAPID (Rapid Climate Change) Program, Meridional Overturning Circulation and Heatflux Array), which will help verify model-based predictions and assessments meridional ocean transports in the Atlantic.

Despite the many issues and challenges outlined above, opportunities exist for major advancements in decadal climate prediction over the next several years. As part of the Coupled Model Intercomparison Project phase 5 
(CMIP5; Taylor et al. 2009), modeling centers around the world are planning coordinated suites of decadal hindcast and prediction experiments covering the period from 1960 to 2035. The results from these prediction experiments will be available to the international research community, and analysis of these results should prove valuable in advancing our understanding of decadal scale variability and predictability. These initialized climate predictions will complement suites of longer term simulations that will explore other aspects of climate system change, including the carbon cycle and other biogeochemical processes and feedbacks that will determine the ultimate degree of climate change in the second half of the $21^{\text {st }}$ century (Meehl and Hibbard 2007; Hibbard et al. 2007). Ultimately, combining such approaches, including the use of higher resolution models capable of simulating regional scale climate phenomena, will provide a unified pathway for ever-improving decadal to centennial climate change predictions.

Skillful decadal predictions will prove invaluable to numerous aspects of society (Vera et al. 2009). Examples include: climate-related health issues, such as the preparation for and possible prevention of the spread of viruses and diseases; planning for possible disasters from increased forest and bush fires, heat waves, droughts, floods and major storms including hurricanes; long-term resource management decisions in industries such as agriculture, forestry, and fisheries; and development of freshwater allocation strategies. Since the decadal time scale is of the same order as monetary investments, financial institutions could use such climate predictions for planning investment strategies.

\section{REFERENCES}

1. Bader, J., and M. Latif, 2003: The impact of decadal-scale Indian Ocean sea surface temperature anomalies on Sahelian rainfall and the North Atlantic Oscillation. Geophys. Res. Lett., 30, doi:10.1029/2003GL018426.

2. Balmaseda, M. \& Co-Authors (2010). "Initialization for Seasonal and Decadal Forecasts" in these proceedings (Vol. 2), doi:10.5270/OceanObs09.cwp.02.

3. Boer, G. J., and S. J. Lambert, 2008: Multi-model decadal potential predictability of precipitation and temperature. Geophys. Res. Lett., 35, doi:10.1029/2008GL033234.

4. Bryan, F. O., G. Danabasoglu, N. Nakashiki, Y. Yoshida, D. H. Kim, J. Tsutsui, and S. C. Doney, 2006: Response of North Atlantic thermohaline circulation and ventilation to increasing carbon dioxide in CCSM3. J. Climate, 19, 2382-2397.

5. Collins, W. D., and co-authors, 2006: The formulation and atmospheric simulation of the Community Atmosphere
System Model Version 3 (CAM3). J. Climate, 19, 21442161.

6. Collins, M., and co-authors, 2006. Interannual to Decadal Climate Predictability: A Multi-Perfect-Model-Ensemble Study. J. Climate, 19, 1195-1203. doi:10.1175/JCLI3654.1.

7. Curry, R. and C. Mauritzen, 2005. Dilution of the northern North Atlantic in recent decades. Science, 308, 1772-1774.

8. Danabasoglu, G., 2008: On multi-decadal variability of the Atlantic meridional overturning circulation in the Community Climate System Model version 3 (CCSM3). J. Climate, 21, 5524-5544, doi:10.1175/2008JCLI2019.1.

9. Delworth, T.L., and M.E. Mann, 2000: Observed and simulated multidecadal variability. Clim. Dyn., 16, 661676.

10. Delworth, T. L., S. Manabe, and R. J. Stouffer, 1993: Interdecadal variations of the thermohaline circulation in a coupled ocean-atmosphere model. J. Climate, 6(11), 1993-2011.

11. Delworth, T. L., and co-authors, 2006: GFDL's CM2 Global Coupled Climate Models - Part 1: Formulation and Simulation Characteristics. J. Climate, 19, 643-674.

12. Domingues, C.M., J.A. Church, N.J. White, P.J. Gleckler, S.E. Wijffels, P.M. Barker and J.R. Dunn, 2008: Improved estimates of upper-ocean warming and multidecadal sea-level rise. Nature, $\mathbf{4 5 3}$, doi:10.1038/nature07080.

13. Deser, C., A.S. Phillips, and J.W. Hurrell, 2004: Pacific interdecadal climate variability: Linkages between the tropics and the north Pacific during boreal winter since 1900. J. Climate, 17, 3109-3124.

14. Doblas-Reyes, F. J., R. Hagedorn, T. N. Palmer, 2005: The rationale behind the success of multi-model ensembles in seasonal forecasting - II. Calibration and combination. Tellus A, 57, 234-252, doi:10.1111/j.16000870.2005.00104.x.

15. Drinkwater, K. F., 2006: The regime shift of the 1920s and 1930s in the North Atlantic. Progr. Oceanogr. 68, 134-151.

16. Emanuel, K., 2005a: Increasing destructiveness of tropical cyclones over the past 30 years. Nature, 436, 686-688.

17. Enfield, D.B., A.M. Mestas-Nuñez, and P.J Trimble, 2001: The Atlantic Multidecadal Oscillation and its relation to rainfall and river flows in the continental US. Geophys. Res. Lett., 28, 2077-2080.

18. Enfield, D.B., and L. Cid-Serrano, 2006: Projecting the risk of future climate shifts. Int. J. of Climatology, 26, 885895.

19. Folland, C.K., and co-authors, 2002: Relative influences of the interdecadal Pacific oscillation and ENSO on the South Pacific convergence zone. Geophys. Res. Lett., 29(13), doi:10.1029/2001GL014201. 
20. Freeland, H. \& Co-Authors (2010). "Argo - A Decade of Progress" in these proceedings (Vol. 2), doi:10.5270/OceanObs09.cwp.32.

21. Giannini, A., R. Saravanan, and P. Chang, 2003: Oceanic forcing of Sahel rainfall on interannual to interdecadal time scales. Science, 302, 1027-1030.

22. Gleckler, P. J., K. E. Taylor, and C. Doutriaux, 2008: Performance metrics for climate models, J. Geophys. Res., 113, D06104, doi:10.029/2007JD008972.

23. Griffies, S. M., and K. Bryan, 1997: Predictability of North Atlantic multidecadal climate variability. Science, 275, 181-184.

24. Hagedorn, R. F. J. Doblas-Reyes, T. N. Palmer, 2005: The rationale behind the success of multi-model ensembles in seasonal forecasting - I. Basic concept. Tellus A, 57, 219233, doi:10.1111/j.1600-0870.2005.00103.x

25. Hakkinen, S., and P. B. Rhines, 2004: Decline of subpolar North Atlantic circulation during the 1990s. Science, 304, 555-559.

26. Hansen, J. E., and co-authors, 2005: Efficacy of climate forcings. J. Geophys. Res. 110, D18104, doi:10.1029/2005JD005776.

27. Hare, S. R., and N. J. Mantua, 2000: Empirical evidence for North Pacific regime shifts in 1977 and 1989. Progr. Oceanogr., 47, 103-145.

28. Hibbard, K. A., G. A. Meehl, P. Cox, and P. Friedlingstein, 2007: A strategy for climate change stabilization experiments. EOS, 88, 217, 219, 221.

29. Hoerling, M. P., J. W. Hurrell, J. Eischeid, and A. Phillips, 2006: Detection and Attribution of $20^{\text {th }}$ Century Northern and Southern African Rainfall Change. J. Climate, 19, 3989-4008.

30. Hsu, W.-R. and A. H. Murphy, 1986: The attributes diagram: A geometric framework for assessing the quality of probability forecasts. Int. J. Forecasting, 2, 285-293.

31. Hurrell, J. W., G. A. Meehl, D. Bader, T. Delworth, B. Kirtman, and B.Wielicki, 2009: A Unified Modeling Approach to Climate System Predition. Bull. Amer. Meteorol. Soc., doi:10.1175/2009BAMS2752.1

32. IPCC, 2007: Climate Change 2007: The Physical Science Basis. Contribution of Working Group I to the Fourth Assessment Report of the Intergovernmental Panel on Climate Change [Solomon, S., D. Qin, M. Manning, Z. Chen, M. Marquis, K.B. Averyt, M. Tignor and H.L. Miller (eds.)]. Cambridge University Press, Cambridge, United Kingdom and New York, NY, USA, 996 pp.

33. Keenlyside, N., M. Latif, J. Junclaus, L. Kornblueh and E. Roeckner, 2008: Advancing decadal climate scale prediction in the North Atlantic. Nature, 453, 84-88.
34. Kirtman, B. P., and D. Min, 2009: Multi-model ensemble ENSO prediction with CCSM and CFS. Mon. Wea. Rev., 137, 2908-2930. doi:10.1175/2009MWR2672.1

35. Knight, J., and co-authors, 2005: A signature of persistent natural thermohaline circulation cycles in observed climate. Geophys. Res. Lett., 32, L20708, doi:10.1029/2005GL024233.

36. Latif, M. \& Co-Authors (2010). "Dynamics of Decadal Climate Variability and Implications for its Prediction" in these proceedings (Vol. 2), doi:10.5270/OceanObs09.cwp.53.

37. Lean, J. L., and D. H. Rind, 2009: How will Earth's surface temperature change in future decades? Geophys. Res. Lett., 36, L15708, doi:10.1029/2009GL038932.

38. Lee, T. C. K., F. Zwiers, X. Zhang, and M. Tsao, 2006: Evidence of decadal climate prediction skill resulting from changes in anthropogenic forcing. J. Climate, 19, 5305-5318.

39. Lu, J., and T. Delworth, 2005: Oceanic forcing of the late 20th century Sahel drought. Geophys. Res. Lett., 32, L22706, doi:10.1029/2005GL023316

40. Lozier, M.S., S. J. Leadbetter, R. G. Williams, V. Roussenov, M.S.C. Reed, and N.J. Moore, 2008: The spatial pattern and mechanisms of heat content change in the North Atlantic, Science, 319, 800-803.

41. Mantua, N. J., S. R. Hare, Y. Zhang, J. M Wallace, and R. C. Francis R C, 1997: A Pacific interdecadal climate oscillation with impacts on salmon production. Bull. Amer. Meteor. Soc., 78, 1069-1079.

42. Micevski, T., S. W. Franks, and G. Kuczera, 2006: Multidecadal variability in coastal eastern Australian flood data. J. Hydrol., 327(1-2), 219-225, doi:10.1016/j.jhydrol.2005.11.017.

43. Meehl, G.A., and K.A. Hibbard, 2007: A strategy for climate change stabilization experiments with AOGCMs and ESMs. WCRP Informal Report No. 3/2007, ICPO Publication No. 112, IGBP Report No. 57, World Climate Research Programme: Geneva, 35 pp.

44. Meehl, G.A. L. Goddard, J. Murphy, R.J. Stouffer, G. Boer, G. Danabasoglu, K. Dixon, M.A. Giorgetta, A. Greene, E. Hawkins, G. Hegerl, D. Karoly, N. Keenlyside, M. Kimoto, B. Kirtman, A. Navarra, R. Pulwarty, D. Smith, D. Stammer, and T. Stockdale, 2010: Decadal prediction: Can it be skillful? Bull. Amer. Meteorol. Soc., doi:10.1175/2009BAMS2778.1.

45. Murphy, J., co-authors, 2010: Towards prediction of decadal climate variability and change. Procedia Environmental Sciences, Vol. 1, Pages 287-304. World Climate Conference - 3, doi:10.1016/j.proenv.2010.09.018. 
46. Palmer, T. N., F.J Doblas-Reyes, R Hagedorn, and A Weisheimer, 2005: Probabilistic prediction of climate using multi-model ensembles: from basics to applications. Philos. Trans. R. Soc. Lond., 360, 1991-1998.

47. Palmer, T. N., F. J. Doblas-Reyes, A. Weisheimer, and M. J. Rodwell, 2008: Toward seamless prediction: Calibration of climate change projections using seasonal forecast. Bull. Amer. Metero. Soc., 89, 459-470.

48. Palmer, T.N., and co-authors, 2004: Development of a European multi-model ensemble system for seasonal-tointerannual prediction (DEMETER), Bull. Amer. Meteor. Soc., 85, 853-872.

49. Palmer, T.N. and co-authors, 2009: Towards the probabilistic earth system model. J. Climate, submitted.

50. Pierce, D. W., Barnett, T. P., Tokmakian, R., Semtner, A., Maltrud, M., Lysne, J., Craig, A., 2004: The ACPI project, element 1: initializing a coupled climate model from observed conditions. Climatic Change, 62, 13-28.

51. Pohlmann H, J. H. Jungclaus, A. Köhl, D. Stammer, J. Marotzke, 2009: Initializing Decadal Climate Predictions with the GECCO Oceanic Synthesis: Effects on the North Atlantic. J. Climate, 22, 3926-3938, doi:10.1175/2009JCLI2535.1.

52. Polyakov, I.V., G.V. Alekseev, L.A. Timokhov, U.S. Bhatt, R.L. Colony, H.L. Simmons, D. Walsh, J.E. Walsh, and V.F. Zakharov, 2004: Variability of the Intermediate Atlantic Water of the Arctic Ocean over the Last 100 years. J. Climate, 17 (23), 4485-4497.

53. Power, S., T. Casey, C. Folland, A. Colman, and V. Mehta, 1999a: Inter-decadal modulation of the impact of ENSO on Australia. Clim. Dyn., 15, 319-324.

54. Power, S., F. Tseitkin, V. Mehta, B. Lavery, S. Torok, and N. Holbrook, 1999b: Decadal climate variability in Australia during the twentieth century. Int. J. Climatol., 19, 169-184.

55. Seager, R., 2007: The Turn of the Century drought across North America: global context, dynamics and past analogues. J. Climate, 20, 5527-5552.

56. Seager, R., Y. Kushnir, C. Herweijer, N. Naik and J. Velez (Nakamura), 2005: Modeling of tropical forcing of persistent droughts and pluvials over western North America: 1856-2000. J. Climate, 18(19), 4065-4088.

57. Seager, R., Y. Kushnir, M. Ting, M. Cane, N. Naik and J. Miller, 2008: Would advance knowledge of 1930s SSTs have allowed prediction of the dust bowl drought? $J$. Climate., 21(13), 3261-3281.

58. Schneider E. K., B. Huang, Z. Zhu, D. G. DeWitt, J. L. Kinter III, B. P. Kirtman, and J. Shukla, 1999: Ocean data assimilation, initialization, and prediction of ENSO with a coupled GCM. Mon. Wea. Rev., 127, 1187-1207.
59. Schlesinger, M.E., and N. Ramankutty, 1994: An oscillation in the global climate system of period 65-70 years. Nature, 367, 723-726.

60. Schubert, S. D., M. J. Suarez, P. J. Pegion, R. D. Koster, and J. T. Bacmeister, 2004: Causes of long-term drought in the United States Great Plains. J. Climate, 17, 485-503.

61. Shukla, J., 2010: A Revolution in Climate Prediction is both necessary and possible. Bull. Amer. Meteor. Soc., in press.

62. Smith, D. M., and co-authors, 2007: Improved surface temperature prediction for the coming decade from a global climate model. Science, 317, 796-799.

63. Stan, C., and B. P. Kirtman, 2008: The influence of atmospheric noise and uncertainty in ocean initial conditions on the limit of predictability in a coupled GCM. J. Climate, 21, doi: 10.1175/2007JCLI2071.1.

64. Sutton, R. T., and D. L. R. Hodson, 2005: Atlantic Ocean forcing of North American and European summer climate. Science, 309, 115-118.

65. Taylor, K., R. J. Stouffer, and G. A. Meehl, 2009: A summary of the CMIP5 experiment design. WCRP, submitted.

66. Trenberth, K. E., 2008: Observational needs for climate prediction and adaptation. WMO Bulletin, 57 (1) 17-21.

67. Trenberth, K.E., and J.W. Hurrell, 1994: Decadal atmosphere-ocean variations in the Pacific. Clim. Dyn., 9, 303-319.

68. Trenberth, K.E., and D.J. Shea, 2006: Atlantic hurricanes and natural variability in 2005, Geophys. Res. Lett., 33, L12704, doi:10.1029/2006GL026894.

69. Trenberth, K. E., J. T. Fasullo, and J. Kiehl, 2009: Earth's global energy budget. Bull. Amer. Meteor. Soc., 90, No. 3, 311-324.

70. Trenberth, K. E., P. D. Jones, P. Ambenje, R. Bojariu, D. Easterling, A. Klein Tank, D. Parker, F. Rahimzadeh, J. A. Renwick, M. Rusticucci, B. Soden, P. Zhai 2007: Observations: Surface and Atmospheric Climate Change. In: Climate Change 2007. The Physical Science Basis. Contribution of WG 1 to the Fourth Assessment Report of the Intergovernmental Panel on Climate Change. [S. Solomon, D. Qin, M. Manning, Z. Chen, M. C. Marquis, K. B. Averyt, M. Tignor and H. L. Miller (eds)]. Cambridge University Press. Cambridge, U. K., and New York, NY, USA, 235-336, plus annex online.

71. Troccoli, A. and T.N. Palmer, 2007: Ensemble decadal predictions from analysed initial conditions. Phil. Trans. Roy. Soc. A, 365, 2179-2191.

72. Venegas, S.A., and L.A. Mysak, 2000: Is there a dominant timescale of natural climate variability in the Arctic? $J$. Climate, 13, 3412-3434. 
73. Vera, C. and co-authors, 2010: World Climate Conference3, Needs Assessment for Climate Information on Decadal Timescales and Longer. Procedia Environmental Sciences, Volume 1, 2010, Pages 275-286, doi:10.1016/j.proenv.2010.09.017

74. Webster, P.J., et al., 2005: Changes in tropical cyclone number, duration and intensity in a warming environment. Science, 309, 1844-1846.

75. Zhang, R., and T. L. Delworth, 2006: Impact of Atlantic multidecadal oscillations on India/Sahel rainfall and Atlantic hurricanes. Geophys. Res. Lett., 33, L17712, doi:10.1029/2006GL026267.

76. Zhang, R., T. L. Delworth, and I. M. Held, 2007: Can the Atlantic Ocean drive the observed multidecadal variability in Northern Hemisphere mean temperature? Geophys. Res. Lett., 34, L02709, doi:10.1029/2006GL028683.

77. Zhang, S., M. J. Harrison, A. Rosati, and A. Wittenberg, 2007: System design and evaluation of coupled ensemble data assimilation for global oceanic climate studies. Mon. Wea. Rev., 135(10), 3541-3564. 